Although no pust-mortem examination could be obtained, the pauses were, I think, the result of some lesion which not only affected the medulla oblongata, but also other parts of the nervous centres, as evidenced by the loss of voice and the difficulty of deglutition. The patient suffered most probably from fatty degeneration of the heart; and the fainting fit, which seemed to have ushered in his fatal illness, may have been one of the cerebral attacks sometimes seen in fatty disease of the heart. When I saw the patient soon after the fit I thought it might have been caused by embolism, and the subsequent symptoms lend some weight to that hasty opinion.

It has been said that hydrate of chloral is a very useful remedy in Cheyne-Stokes respiration. It so happened this patient had been taking hydrate of chloral when the respiratory pauses came on, and it was fully tried, but without any good result. The patient was ordered plenty of nutriment, and medicines of various kinds were prescribed; but the medicine from which he derived the greatest benefit was dilute nitric acid in a bitter infusion. This mixture sustained his strength, freed him from the troublesome throat mucus, and quite subdued the cough, thus rendering him more comfortable in his latter days. I tried the inhalation of nitrite of amyl with persistency in this and a similar case, but unfortunately with no apparent benefit. The nitrite of amyl inhalations may, however, be of use in Cheyne-Stokes respiration proper, where the ascending and descending rhythm of inspiration are well marked. The inhalations were of great use in a case of this kind which $I$ had under treatment more than five years ago. The patient suffered from intense renal dropsy with great orthopnoea, the breathing during the last few weeks of his life assuming wellmarked Cheyne-Stokes respiration. This patient derived much comfort and relief from time to time from the inhalation of four or five drops of the amyl. On several occasions it restored and reinvigorated the breathing when it was about cease.

The respiratory pause, it would seem, may be the result of either functional derangement or organic disease, but evidently more frequently the result of the latter. In these cases $I$ am of opinion that treatment, no matter how judicious, is of little or no avail ; for when this symptom sets in it is generally the precursor of dissolution. I might add that it is a most impressive symptom, and requires to be only once seen to be for ever remembered.

Lincoln.

\section{A CASE OF TRUE EASTERN LEPROSY.}

\section{BY JAMES STARTIN, M.R.C.S. ENG., \&e.}

TYPICAL cases of true Eastern leprosy of the anæsthetic variety are rarely seen in this country. The notes of the following case may be of much interest to the profession, especially as there is, at the present time, a considerable controversy going on as to the true etiology of the disease in this country and abroad, some authorities ascribing the cause to the eating of bad fish.

E. McG - aged forty-six, a native of Derbyshire, went out to India in 1858 at the age of twenty-three years with his regiment, and he remained out thirteen years. "His father and mother are both natives of Ireland, and there was no family history of syphilis or skin disease. The patient stated that he himself contracted syphilis whilst in India, and was cured there. He was vaccinated three times in India from natives, and twice at home, and he has not had small-pox. He came home to England about ten years ago. He then noticed, as he was on his way home, a slight mottling of the skin, and felt a numbness in the hands and arms, and a feeling of pricking as of pins and needles in the fingers and arms. He states he had plenty of food and very little fish, a few sardines and other tinned fish, but this he had only occasionally, and it was fresh. But he had no fresh vegetables fur some years. He had eaten a good deal of Indian corn made up as food at one time or another, and he does not attribute his disease to the eating of bad fish, as he says he had so little fish of any kind. He had had several bad attacks of ague and fever, which he said much weakened him, and he was often exposed very much to the climate.

When he first came under my notice he was covered with an eruption of brown maculæ or spots about the size of a sixpenny-piece, very slightly raised above the level of the surrounding skin. He had also patches of brawny brownsh skin quite insensible to a prick of a needle; in their centre, in different parts of the body, on the anterior surface of the bend of the elbows and forearm, were patches about eight inches long and three broad, also on the side of the neck, face, and ears, but smaller in size. The cutaneous nerves of the arm and forearm and the ulnar nerve could be seen and felt as tense and swollen cords, knotty and hard to the touch-a very characteristic and diagnostic feature in this disease, and being very well-marked in this case. He had also a tuberculous leprous-looking sore on the left leg on the inner side, about four inches below the knee-joint, and he had also a brown anæsthetic patch over the left knee. The next important feature of the disease was that of considerable wasting of the muscles between the thumb and index-finge and the intermetacarpal spaces, and he lost the power of adducting or closing his fingers, or even of holding any thing in his hands. A pail of water he would let fall trom want of power to keep his fingers closed. The outer side of the little-finger and hand was quite insensible to puncture with a needle. The patient complained of feeling much depressed at times. The mucous membrane of the mouth, tongue and lips was much affected with tuberculous patches, and very tender and sore at all times. At this period of the case I had a drawing taken of the patient, showing most of the features described. With regard to the treatment, I must say he has very much improved under the continued doses of chaulmoogra oil, taken first as an emulsion; then, as it returned very much, the capsules, of which he took as many as twenty a day; and he well rubbed the oil into the skin; he also took large doses of quinine, which he said he felt much better for.

He has now regained the use of his hands, and the anæsthetic patches are losing their insensibility, and the patient tells me that he feels much better and stronger, and the eruption is disappearing.

Now, with respect to diet, I ordered him, whilst he was in the hospital, a good diet, unstimulating, with plenty of fresh vegetables, which he much enjoyed, having had so little of them. As to the influence of bad fish as a common cause of origin of this disease, I confess I am very sceptical, this case in point of fact (and there could not be a more typical case, as was said by Sir Joseph Fayrer, Mr. Erichsen, Mr. Hutchinson, and several other eminent members of the profession, to whom $I$ had the pleasure of showing it at the Medical and Chirurgical and Pathological Societies) could not be possibly ascribed to the eating of bad fish, for he had none. But I do firmly believe that the want of fresh rege table food, and continued attacks of fever and ague destroying the nerve vitality, to be the principal causes of this case, and of others of leprosy. Most of the cases of this terrible disease occur in India, and, as I am reliably informed, the natives live almost on nothing, or whatever they can get, and it is amongst this class the disease is most prevalent. What can the supporters of the fish theory say to the fact that the natives on the borders of the great desert of Sahara never eat fish, and yet they get leprosy in its worst forms. And, again, the natives of Rawal-Pindi in the Punjab in India, and the natives who dwell on the Naga Hills in Assam, do not eat fish, and yet they get it too. Now the natives or the "Nuggs," who live in Arakan, live on fish, yet leprosy is seldom if ever seen among them. These and other important facts which I have elicited from reliable sources, from men who have seen many years' active service among the natives of India and Northern Africa, completely upset, in my opinion, the theory of the eating of bad fish as the origin of true leprosy. Neither do I believe leprosy to be a contagious disease.

Sackville-street, $\mathrm{w}$.

\section{DECALCIFIED BONE DRAINAGE-TUBES.}

\section{BY SURGEON SHIRLEY DEAKIN, F.R.C.S.ENG., I.M.D.}

IN an Indian station, far removed from surgical instrument makers, drainage-tubes are not often procurable, gutta-percha tubing even not being included among the articles of the small local store which does duty for a shop. Though native workmen are clever enough at copying an article from a pattern, they are very stupid in working from an engraving. Further, as regards bone drainage-tubes, all respectable Hindoos have serious caste objections to touching bones, so 